\title{
Impact of activity-based workplaces on burnout and engagement dimensions
}

Rianne Appel-Meulenbroek

Department of the Built Environment, Eindhoven University of Technology, Eindhoven, The Netherlands

Theo van der Voordt

Department of Management in the Built Environment, Faculty of Architecture, Delft University of Technology, Delft, The Netherlands and

Center for People and Buildings, Delft, The Netherlands

Rik Aussems

$v b \& t$ Vastgoedmanagement bv, Eindhoven, The Netherlands

Theo Arentze

Department of the Built Environment, Eindhoven University of Technology, Eindhoven, The Netherlands, and

Pascale Le Blanc

Industrial Engineering and Innovation Sciences, Eindhoven University of Technology, Eindhoven, The Netherlands

\footnotetext{
Abstract

Purpose - This paper aims to explore, which characteristics of activity-based offices are related to the position of workers on the burnout - engagement continuum.

Design/methodology/approach - Literature review and an online survey amongst knowledge workers in the Netherlands, which provided data of 184 respondents from 14 organisations. The data has been analysed by descriptive statistics, bivariate analyses, factor analyses and path analysis, to test the conceptual model.

Findings - Five physical work environment constructs were identified of which three showed to have significant relations with employees' position on one of the three dimensions of the burnout - engagement continuum. Distraction has a direct and indirect (through overload) negative relation with the individual strain (meaning increased exhaustion). Office comfort has indirect positive relations (through recognition and appreciation) with the interpersonal strain (meaning increased involvement). The possibility for teleworking has an indirect positive relation (through control) on the self-evaluation strain (meaning increased efficacy).

Practical implications - The findings show that in the design and management of a healthy physical work environment, corporate real estate managers and human resource managers should particularly pay

(C) Rianne Appel-Meulenbroek, Theo van der Voordt, Rik Aussems, Theo Arentze and Pascale Le Blanc. Published by Emerald Publishing Limited. This article is published under the Creative Commons Attribution (CC BY 4.0) licence. Anyone may reproduce, distribute, translate and create derivative works of this article (for both commercial and non-commercial purposes), subject to full attribution to the original publication and authors. The full terms of this licence may be seen at http://creativecommons.org/licences/by/4.0/legalcode
}

Burnout and engagement dimensions

Received 13September 2019 Revised 2 March 2020

11 May 2020

18 June 2020

Accepted 30 June 2020

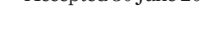


JCRE 22,4

attention to lowering distraction, providing comfortable workplaces and considering the option of teleworking to some extent.

Originality/value - This paper provides new insights into the impact of distinct activity-based workplace characteristics on workers' position on the burnout - engagement continuum.

Keywords Burnout, Engagement, Health, Distraction, Comfort, Activity-based workplaces

Paper type Research paper

\section{Introduction}

According to Maslach and Leiter (1997), people's psychological relationship to their job can be positioned on a continuum between the negative experience of burnout and the positive experience of engagement. Burnout can be defined as a state of mental and physical exhaustion caused by one's professional life (Freudenberger, 1974). It is associated with psychological and physical health problems (Schaufeli and Enzmann, 1998; Shirom et al., 2005), job dissatisfaction, low levels of commitment and destabilisation of one's work-life balance (Grawitch et al., 2006), increased sickness absence (Schaufeli et al., 2009) and reduced productivity and job performance (Maslach and Leiter, 2008). The opposite on the continuum, work engagement, is defined as a positive, fulfilling, work-related state of mind that is characterised by vigour, dedication and absorption (Schaufeli et al., 2002). The engagement has been associated with high levels of energy, pleasure, activation and commitment (Parker and Griffin, 2011). Engaged workers appear to be more open to new experiences, explore their work environments and, in doing so, become more creative (Fredrickson, 2001).

In a present-day competitive society with its war on talent, employees are recognised as the most valuable assets of the organisation. Regarding corporate real estate (CRE) management, it is, thus, important to better understand the role of the physical environment in reducing the risk of burnout and instead of stimulating engagement. In line with the person-environment fit theory, a suboptimal fit between the work environment and employees' needs and abilities would otherwise result in stress (Edwards et al., 1998). This could mean that a poor office workplace might push people towards the negative side of the burnout-engagement continuum (BEC). So far, studies on healthy workplaces have focussed mostly on isolated design aspects such as plants, indoor climate and sick building syndrome (Arif et al., 2016). Knowledge about the impact of activity-based workplaces (ABW) on health is very limited (Engelen et al., 2019). We only found one study that included the BEC (Van Steenbergen et al., 2018). This before-after study (amongst 126 employees of a large Dutch provider of financial services) showed new ways of working to be beneficial in reducing mental demands and workload. It did not harm relationships with supervisors and co-workers, but autonomy and possibilities for professional development decreased. Burnout and work engagement remained stable over time. The current paper further explores, which characteristics of ABW influence employees' position on the BEC. A literature-based conceptual model is tested through path analysis for relations and effect sizes. The model incorporates physical work environment characteristics as independent variables, job-related situational characteristics as mediators and individual characteristics as control variables.

\section{Burnout and engagement: dimensions and influencing factors}

Maslach and Leiter (1997) distinguished three sub-dimensions in their BEC theory as follows: individual strain (exhaustion - energy), interpersonal strain (depersonalisation involvement) and self-evaluation strain (inefficacy - efficacy). Exhaustion refers to feelings 
of being overextended and depleted of one's emotional and physical resources. It is related to work fatigue, i.e. extreme physical, mental and/or emotional tiredness and reduced functional capacity (Frone and Tidwell, 2015). It is the most widely reported and most thoroughly analysed dimension (Maslach et al., 2001; Maslach and Leiter, 2008), with energy as the engagement opposite. Depersonalisation refers to a negative or excessively detached response to various aspects of the job (Maslach et al., 2001). To make this depersonalisation dimension applicable in multiple industries, Schaufeli et al. (1996) replaced depersonalisation by the term cynicism, reflecting a distant attitude towards work, with involvement as the engagement opposite. Inefficacy refers to feelings of incompetence and declined personal achievements at work (Maslach et al., 2001; Maslach and Leiter, 2008), with efficacy as the engagement opposite. The three dimensions are included as dependent variables in our conceptual model, see Figure 1.

The antecedents of burnout and engagement are often classified into individual factors and situational factors (Maslach et al., 2001; Bakker and Demerouti, 2008). In this paper, the individual variables are incorporated as control variables, whereas the situational characteristics are treated as mediators between the BEC dimensions and the characteristics of the physical work environment (the independent variables). Besides being antecedents of the BEC, these situational factors are likely to be influenced by the ABW as well. See Figure 1 for the full model that is tested in this study. The next literature review will explain the four main hypotheses and the variables chosen for each box to test these hypotheses.

\section{Activity-based workplaces}

In the past decades, various new office concepts have been developed to support optimal use of the available space and to empower knowledge workers to work more efficiently and effectively. ABW is characterised by the shared use of different types of workplaces that are supposed to optimally fit with different office tasks, mainly in open and semi-open settings. The additional support by modern information and communication technology (ICT) provides workers more autonomy and freedom to work how, when and where they find this most appropriate (Van der Voordt, 2004; Haapakangas et al., 2019). Such new ways of (flexible) working may provide better opportunities for communication, collaboration and interaction (Engelen et al., 2019), but are also associated with less social cohesion amongst co-workers, referring to a lower sense of community. Complaints include lack of privacy and concentration, loss of storage space and loss of personal and group identity by not being

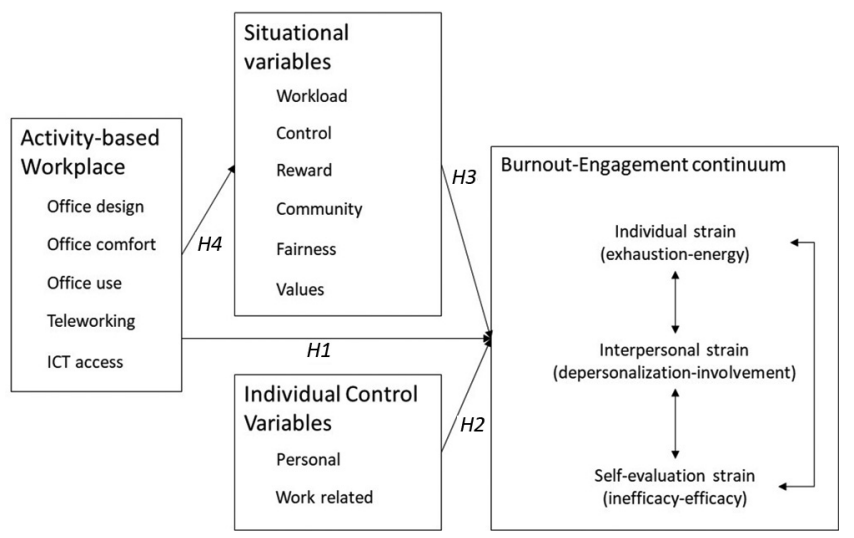

Figure 1. Conceptual model 
JCRE 22,4

282

able to personalise the workspace (Gorgievski et al., 2010). In particular distraction by conversations of colleagues and phone calls and lack of visual and auditory privacy cause dissatisfaction amongst employees (Brunia et al., 2016). So far, it remains unclear whether $\mathrm{ABWs}$ would have a positive or negative influence on workers' position on the BEC and how their characteristics relate to the three distinct dimensions.

Vos et al. (1999) and De Croon et al. (2005) argue that offices can be described according to three constructs, being office location (place of work: at the office versus teleworking at home/third places), office layout (space design i.e. open plan, cellular offices, team offices or combi-offices) and office use (personal desks versus non-assigned desks). Haynes (2007a) developed a model with two constructs as follows: the physical environment and the behavioural environment, each with two subcomponents, respectively, office layout and office comfort and interaction and distraction. These authors did not specifically study ABWs, which is, perhaps, why ICT support was not part of their frameworks. However, it is an essential element of ABWs. Building on these references, the ABW component of the conceptual model is split into five main constructs as follows (Figure 1): office layout, office comfort, office use, teleworking and ICT access.

Office layouts that do not fit with user needs and behaviour may result in feelings of lack of control and community, and thus higher levels of workplace stress (Vischer, 2007). Based on a review of 24 studies, De Croon et al. (2005) conclude that there is much evidence that working in open workplaces reduces the office worker's psychological privacy and some evidence that working in open workplaces and close distances between workstations intensify cognitive workload and/or worsen interpersonal relations. They also found the relationship between these two design aspects and performance to be inconsistent. So potentially, office layout relates to all three dimensions of the BEC. In ABWs the variety of workplaces may increase feelings of autonomy, which has a positive relationship with work engagement (Maslach and Leiter, 2008). Haynes et al. (2017) even showed that the availability of a variety of spaces had the greatest impact on productivity (the selfevaluation strain).

Office comfort is usually related to ambient factors (Seppänen and Fisk, 2006) and ergonomics (Kroemer and Kroemer, 2016). Indoor climate and lighting are often ranked highest in the office's impact on perceived health and performance (Bae et al., 2017). Kroemer and Kroemer (2016) point out that office ergonomics can lower stress, increase personal engagement and raise performance as well. Besides comfort, the ability to adjust these factors to individual preferences may contribute to feelings of control and fairness (e.g. equal treatment regardless of job rank) (Clements-Croome and Li, 1997) and as such may be related to dimensions of the BEC as well, following Maslach and Leiter (2008).

Office use regards both interaction and distraction and desk-sharing. Interaction and distraction are highly interrelated. One person's interaction is another person's distraction (Haynes and Price, 2004) and can decrease feelings of privacy. Both social and work interactions may be linked to feelings of community, while distraction by interruptions, feelings of crowding and noise and feelings of lack of control and privacy may be related to all three dimensions of the BEC (Bakker et al., 2014; Haynes, 2007b). The ABW environment adds additional relevant use-aspects, as workers have to share workspaces and are expected to switch between different workspaces. The evidence of whether desk-sharing increases overload is still inconsistent but provided by some studies according to De Croon et al. (2005). Only 4\% of workers switch workstations during the day (Hoendervanger et al., 2016). Apparently, this ABW-rule is not perceived as a positive demand and might cause stress. Additionally, it determines who sits by whom and could, thus, relate to the interpersonal dimension. 
Teleworking may result in more autonomy where to work, and thus in less interaction between staff members, which may reduce the possibility to obtain social support and feedback. It also may indicate that work is never completed (Demerouti et al., 2014; Peters and Van der Lippe, 2007). Teleworking is shown to create loneliness, irritability, worry and guilt and stress (Mann and Holdsworth, 2003). Besides these potential links to the individual and the interpersonal dimensions of the BEC, research has shown that telework intensity has consequences for the efficacy dimension (Hoornweg et al., 2016).

Last, inappropriate ICT facilities, information overload, the pressure to respond quickly to e-mails and social media and insufficient skills to cope with these issues may result in perceived work overload (Rennecker and Derks, 2012; Demerouti et al., 2014). As a consequence, a relationship with at least the individual dimension of the BEC can be expected. ICT access has also been shown to relate to the productivity of workers (Nurmilaakso, 2009). Intuitively, technology such as intranet and cloud computing could relate to the interpersonal dimension as well, as people can exchange information this way.

Therefore, we pose:

H1. ABW characteristics have a direct effect on an employee's position on the BEC.

\section{Individual control variables}

Not all individuals are equally likely to get a burnout. Therefore, various individual characteristics are included in the model as control variables. Maslach et al. (2001) pointed out that the level of burnout amongst younger employees is higher than amongst those over 30 or 40 years old. This suggests that workers are more at risk to burn out earlier in their careers. Men score a little higher on the cynicism dimension of burnout, whereas women score higher on the exhaustion dimension of burnout (Maslach et al., 2001), so gender matters as well. Also, employees with higher levels of education and singles are more likely to experience burnout (Maslach et al., 2001). With regard to personality, Schaufeli and Enzmann (1998) refer to numerous studies that included one or more of the Big five personality characteristics. For example, people who score high on neuroticism are more sensitive to stress (Albrecht, 2010) while extraversion and conscientiousness are directly associated with a higher level of well-being (Parent-Lamarche and Marchand, 2019).

Besides personal characteristics, individual job-related aspects could be relevant as well. Knowledge workers have to be productive in three different main activities, namely concentrated work, formal interactions and informal interactions (De Been et al., 2016). It might differ between workers how important each activity is, which could be relevant to the interpersonal strain (interactions) and, perhaps, also to the other BEC dimensions. Also, Maslach et al. (2001) mention that burnout is higher amongst people in lower job ranks, who have little participation in decision making. Also, work experience acquired through on-thejob-training has been shown to lead to greater productivity (Quińones et al., 1995), and thus may affect the self-evaluation strain.

Therefore, we pose:

H2. Individual control variables affect an employee's position on the BEC.

\section{Situational variables}

Bakker et al. (2014) found that stressful aspects of the work situation are even more important predictors of burnout than personal control variables. Maslach and Leiter (1997) identified six domains of situational work environment factors as follows: stress, control, 
JCRE 22,4

reward, community, fairness and values. TNO (2015) showed that job stress is mainly caused by insufficient autonomy (44\%) and excessive workload (38\%). High job demands and lack of control may result in job stress, which has been recognised as an early predictor of burnout and as an impairment of physical health, psychological well-being and work performance (Kahn and Byosiere, 1992). Reward refers to the power of reinforcements to shape behaviour and stress (Leiter and Maslach, 2005). A high level of a perceived community may reduce stress (Schaufeli and Bakker, 2004), e.g. by social support from coworkers and supervisors. Fairness emerged from the literature on equity and social justice. Unfairness occurs when there is the inequity of workload or reward, when there is cheating or when evaluations and promotions are handled inappropriately (Maslach et al., 2001). The sixth domain - Values - picks up the cognitive-emotional power of job goals and expectations (Leiter and Maslach, 2005). When a conflict of values occurs at the job, workers will find themselves making a trade-off between the work they want to do and the work they have to do (Maslach et al., 2001; Maslach and Leiter, 2008):

\section{H3. Situational variables affect an employee's position on the BEC.}

Besides a direct relation between situational variables and the $\mathrm{BEC}$, the office environment is likely to relate to these situational variables as well, so they are included as mediators in the conceptual model. For example, Van der Voordt (2004) warns for additional workload due to desk sharing and switching, as workers lose time by finding available workspaces and adjusting their settings to their own preferences. Then, teleworking could reduce social support (community) and increase workload (Demerouti et al., 2014; Peters and Van der Lippe, 2007). Oseland (2009) states that office design should provide workers with a feeling of control through both the personal space and the way they are allowed to use the office. Access to ICT and teleworking might also increase feelings of control. Reward not only relates to financial payment but also to a feeling of being appreciated. Supportive office design and comfort might add to this feeling (Rothe et al., 2011). On the other hand, an office design that does not fit with user needs and behaviour may result in a lack of feelings of a community (Vischer, 2007). Studies on activity-based offices also refer to fairness and values, for example, by mentioning that $A B W$ is not considered as fair if not all levels in the organisation give up their dedicated desks (Appel-Meulenbroek et al., 2015).

So last, we pose:

H4. ABW characteristics have an indirect effect on employee's position on the BEC, via the situational variables.

\section{Research methods \\ Sampling and measuring}

To test the conceptual model and hypotheses, quantitative data has been collected by means of an online questionnaire. CRE managers, facility-managers and human resource managers of 14 organisations with an ABW concept were asked to distribute the questionnaire to knowledge workers within their organisation, between 10 July and 4 September 2018. In total, 184 employees completed the full questionnaire with 85 questions and statements.

Regarding the ABW environment, respondents were asked to respond to a number of statements, using a five-point scale. The office layout is operationalised by workplace variety, workplace availability, openness, the distance between workplaces and facilities. The responses to eight statements (e.g. "The variety of workspaces allows me to choose the workspace that best fits the activity" and "In my opinion, the spatial design of the office 
environment is optimal") range from (strongly) disagree till (strongly) agree. Office comfort has been measured by 10 statements on ambient factors (e.g. air quality, ventilation, personal control), ergonomic furniture (desks and chairs) and overall comfort, with responses ranging from (very) uncomfortable till (very) comfortable. Office use has been operationalised by the frequency of choosing a workplace that fits best with the activity, leaving behind a clean desk, claiming a workplace by personalisation, interaction, distraction, the experience of excessive noise and opportunities to isolate themselves from colleagues, using 10 items (e.g. "during work, I interact with colleagues on a social level" and "during work, I am easily distracted by colleagues"). For teleworking two items were used ("I can work at home" and "I can work between home and the office" at any given time) and for ICT three items (e.g. "I can use cloud computing to store my data"), both with answers ranging from never till always.

The individual control variables age, gender, level of education and household composition were measured by closed questions. Personality has been measured by the Big Five Inventory (BFI-10) questionnaire (Rammstedt and John, 2007), job rank by marking one out of six choices (e.g. trainee, board member, other) and work experience by indicating years of deployment at the current employer. Activities, in particular communication and concentration, were measured by their importance on a five-point scale. The six situational variables have been measured by 11 statements from the areas of work-life scale measure (AWS) (Leiter and Maslach, 2003), e.g. "I have too much work to do" and "I perceive my social rewards (e.g. appreciation, respect) as being sufficient for the work I do".

For the employees' position on the BEC, 15 statements (seven-point scale) were adopted from the Utrecht Burnout Scale (UBOS, Brenninkmeijer and Van Yperen, 2003). The UBOSGS is very similar to the widely used MBI-GS that assesses the three BEC dimensions (Maslach and Leiter, 2008). See Aussems (2019) for the full survey set-up.

\section{Data analysis}

Checks were conducted on sufficient sample size, multicollinearity and singularity, outliers, normal distribution, linearity and homoscedasticity, to define, which statistical analyses would be most appropriate and what kind of data reduction could be applied before the main analysis. Scale constructs were checked on internal consistency by Cronbach's alpha, which showed to be sufficiently high $(>0.70)$ for most variables. Distraction conditions in the office (close proximity) lowered Cronbach's alpha of the office layout construct from 0.81 to 0.71 . Because of its expected impact based on the many office noise studies, it was kept as a separate "proximity" variable. The office use items $(\alpha=0.34)$ were entered into a factor analysis (Principal Axis Factoring and Direct Oblimin with Kaiser normalisation) to reduce the set of variables while assuming a latent construct of office use. This provided four factors, labelled interaction, distraction, desk-switching and claiming, explaining $62.8 \%$ of the total variance. The six situational variables were reduced by factor analysis as well due to low Cronbach's alpha values ( $\alpha=0.634$ (control), 0.540 (rewards) and 0.306 (community) with single items for the other three variables). The factor analyses reduced the set of variables to four factors, explaining $62.5 \%$ of the total variance. Recognition includes financial and social rewards and fairness. Overload and values group together. The control contains all original control items, while appreciation combines the social support items (from co-workers and from supervisors) with intrinsic rewards (pride). Table 1 shows the final variables that were used for further analyses. A path analysis was used as an extension of multiple regression analysis to simultaneously analyse the direct and indirect effects of ABWs on all three strains of the BEC and the relationships between the strains while controlling for individual variables and placing the situational variables as mediators. A 
JCRE 22,4

\begin{tabular}{|c|c|c|c|}
\hline Variables & Individual strain & Interpersonal strain & Self-evaluation strai \\
\hline \multicolumn{4}{|l|}{ Workplace characteristics } \\
\hline Office layout & 0.100 & 0.036 & 0.060 \\
\hline Proximity & -0.077 & -0.030 & $-0.176^{*}$ \\
\hline Office comfort & 0.023 & 0.135 & $0.144^{*}$ \\
\hline \multicolumn{4}{|l|}{ Office use } \\
\hline - Interaction & 0.078 & 0.085 & $0.168^{*}$ \\
\hline - Distraction & $-0.282^{* *}$ & $-0.176^{*}$ & -0.110 \\
\hline - Desk-switching & 0.008 & 0.074 & $0.210^{* *}$ \\
\hline - Claiming & -0.086 & -0.103 & -0.0 .37 \\
\hline Possibility to telework & -0.015 & 0.020 & -0.006 \\
\hline ICT access & 0.091 & 0.076 & $0.155^{*}$ \\
\hline \multicolumn{4}{|l|}{ Individual control variables } \\
\hline \multicolumn{4}{|l|}{ Demographics } \\
\hline - Age & 0.106 & 0.109 & $0.277^{* *}$ \\
\hline - Gender & $Z=-0.354^{* *}$ & $Z=-0.131$ & $Z=-0.767$ \\
\hline - Education level & 0.046 & -0.066 & -0.064 \\
\hline - Household composition & 0.050 & -0.024 & 0.061 \\
\hline \multicolumn{4}{|l|}{ Personality } \\
\hline - Extraversion & 0.121 & $0.221 * *$ & $0.263^{* *}$ \\
\hline - Agreeableness & 0.087 & $0.212^{* *}$ & $0.198^{* *}$ \\
\hline - Conscientiousness & 0.061 & $0.188^{*}$ & $0.225^{* *}$ \\
\hline - Neuroticism & $-0.202 * *$ & $-0.150^{*}$ & $-0.314^{* *}$ \\
\hline - Openness & 0.015 & $0.231^{* *}$ & $0.158^{*}$ \\
\hline \multicolumn{4}{|l|}{ Work-related variables } \\
\hline - Job Rank & $Z=-0.218$ & $Z=-0.036$ & $Z=-0.133$ \\
\hline - Work experience & 0.038 & 0.052 & $0.339^{* *}$ \\
\hline - Activities_concentration & -0.039 & 0.112 & 0.083 \\
\hline - Activities_informal interaction & 0.097 & $0.191 * *$ & 0.080 \\
\hline - Activities_formal interaction & 0.028 & $0.307 * *$ & 0.010 \\
\hline \multicolumn{4}{|l|}{ Situational variables } \\
\hline Recognition & $0.228 * *$ & $0.297 * *$ & $0.146^{*}$ \\
\hline Overload & $0.365^{\text {** }}$ & 0.106 & -0.037 \\
\hline Control & 0.130 & $0.196^{* *}$ & $0.370^{* * *}$ \\
\hline Appreciation & 0.054 & $0.367 * *$ & $0.290 * *$ \\
\hline
\end{tabular}

Table 1.

Bivariate correlations of workplace characteristics and individual and situational variables with BEC dimensions
Notes: ** $=$ significant at 0.01 level; * = significant at 0.05 level. A test on interrelationships between the three BEC dimensions showed two correlations to be significant: between the individual and interpersonal strain $\left(0.419^{* * *}\right)$ and between the self-evaluation and interpersonal strain $\left(0.289^{* *}\right)$. The correlation between individual strain and self-evaluation strain was not significant. As Maslach and Leiter (1997) did assume relations between all three strains, we stick to including all three relations in the path model, with arrows in both directions

major advantage is that this method can estimate direct and indirect effects simultaneously and allows them to include several dependent variables. To select, which variables and relations to include in the path analysis, first bivariate correlation analyses were performed for all possible relations in the model, to check whether the theoretical assumptions are replicated in this sample. A minimum sample size for regression type analyses is $\mathrm{N}=$ $50+8 \mathrm{k}$, in which $\mathrm{k}$ is the number of predictors or independent variables (Tabachnick and Fidell, 2007). The variable with the highest amount of (15) predictors in the path model is the self-evaluation strain and $50+8 * 15=170$ still falls within the sample size of 184 respondents. 


\section{Results}

Sample characteristics

The sample contains a larger share of women (56.0\%) compared to the whole Dutch work population $(46 \%)$. The respondents are between 20 and 66 years of age $(\mathrm{M}=43.7 ; \mathrm{SD}=$ 11.8), whereas the overall average age of Dutch workers is 42.1 years; the difference is not significant. The majority of respondents $(77.7 \%)$ is highly educated, $20 \%$ is single, $76.6 \%$ is living together/married without children $(32.1 \%)$ or with children $(44.6 \%)$ and $3.3 \%$ marked "other". The majority of respondents perceive themselves as outgoing and sociable $(72.8 \%)$, indicating extravert personalities. For agreeableness, most respondents see themselves as generally having trust $(91.8 \%)$. The majority of respondents identify themselves as doing a thorough job (91.8\%) and, thus being conscientious. For neuroticism, the majority of respondents identify themselves as being relaxed and handling stressful situations well $(66.3 \%)$, rather than being nervous easily $(6.5 \%)$. With respect to openness, the majority of respondents identify themselves positively too. Work experience averages 13.1 years $(\mathrm{SD}=$ 11.4). Most respondents are regular employees $(71.2 \%)$, with $20.7 \%$ being a manager/ supervisor. The importance of the three activities (concentration, formal and informal communication) is very similar for all respondents as follows: the average is a little above 4 (= important) with standard deviations of approximately 0.7 .

In general, the mean scores on the BEC traits were on the positive side of the seven-point scale, so pointing towards an engaged sample with relatively low burnout symptoms. The individual dimension scored a 6.13 average $(\mathrm{SD}=0.74)$, the interpersonal dimension 6.36 $(\mathrm{SD}=0.82)$ and the self-evaluation dimension $5.70(\mathrm{SD}=0.713)$

\section{Bivariate correlation analyses}

The findings of the bivariate analyses (Table 1) indicate significant relationships between most ABW constructs and all situational variables with at least one of the BEC dimensions. Only office layout, desk claiming and teleworking did not show any significant direct correlations. However, office layout and teleworking do show potential for an indirect relation mediated by situational variables, as they correlated, respectively, with recognition and with control and appreciation (Table 2). Again, desk claiming did not, and therefore is left out of the path analysis, as there is also no existing proof in previous studies relating this specific aspect of office use to any of the situational variables or the BEC.

The individual control variables age, gender and personality also showed to be significantly correlated with at least one of the BEC dimensions, whereas education level

\begin{tabular}{lcccc}
\hline Workplace characteristics & Recognition & Overload & Control & Appreciation \\
\hline Office layout & $0.149^{*}$ & 0.071 & 0.103 & 0.037 \\
Proximity & 0.027 & -0.007 & -0.097 & -0.078 \\
Office comfort & $0.255^{* *}$ & -0.090 & 0.127 & $0.233^{* *}$ \\
Office use & & & & \\
- Interaction & 0.093 & 0.060 & 0.044 & 0.112 \\
- Distraction & -0.069 & $-0.153^{*}$ & -0.100 & -0.038 \\
- Desk-switching & 0.107 & -0.056 & 0.143 & 0.060 \\
- Claiming & -0.089 & 0.030 & -0.091 & -0.116 \\
Possibility to telework & 0.114 & -0.122 & $0.205^{* *}$ & $0.170^{*}$ \\
ICT access & 0.117 & -0.091 & 0.128 & 0.118
\end{tabular}

Table 2.

Correlations between workplace characteristics and

Notes: $* *=$ significant at 0.01 level; $*=$ significant at 0.05 level situational variables

Burnout and engagement dimensions

287 
JCRE 22,4

288

and household composition did not. Regarding the five work-related variables, work experience and formal and informal interaction showed to be significantly correlated, with, respectively, the self-evaluation strain and the interpersonal strain.

\section{Path analysis}

The model to be tested, based on theory and bivariate analyses, is presented in Figure 2.

Figure 3 shows the relations that remained significant in the path analysis, with the standardised coefficient for each link. The $R^{2}$ is 0.20 for the individual strain, 0.25 for the interpersonal strain and 0.31 for the self-evaluation strain. So, a maximum of almost a third of the variation in the BEC dimension is explained by the independent variables. The ABW constructs explain only a few per cent of the variation in the situational variables (recognition $R^{2}=0.07$; overload $R^{2}=0.02$; control $R^{2}=0.04$; appreciation $R^{2}=0.07$ ). Three ABW constructs showed significant relations with a BEC dimension, namely distraction (office use), Office comfort and teleworking. The interpersonal strain has (bidirectional) links both with the individual $(\beta=0.31)$ and the self-evaluation strain $(\beta=0.12)$, but again the relationship between the individual and the self-evaluation strain was not significant.

Distraction has a direct negative relationship with the individual strain $(\beta=-0.21)$ indicating that when distraction increases, exhaustion increases. More peculiar is the indirect relationship through overload, where distraction decreases overload $(\beta=-0.15)$ and increases energy $(\beta=0.22)$. Also, women score higher on individual strain (more energy) than men $(\beta=-0.18)$.

Office comfort only has indirect relations, both through increasing feelings of recognition ( $\beta=0.23$ ) and appreciation $(\beta=0.20)$, with increased involvement (the interpersonal strain, $\beta=0.18$ and 0.17$)$. Workers for who formal meetings are more important $(\beta=0.23)$ or who have more open personalities ( $\beta=0.15$ ) also score higher on the interpersonal strain.

The possibility for teleworking relates to increased feelings of control $(\beta=0.21)$, which relates to efficacy (the self-evaluation strain, $\beta=0.20$ ), so again only an indirect relation.

Figure 2.

Model used for path analysis

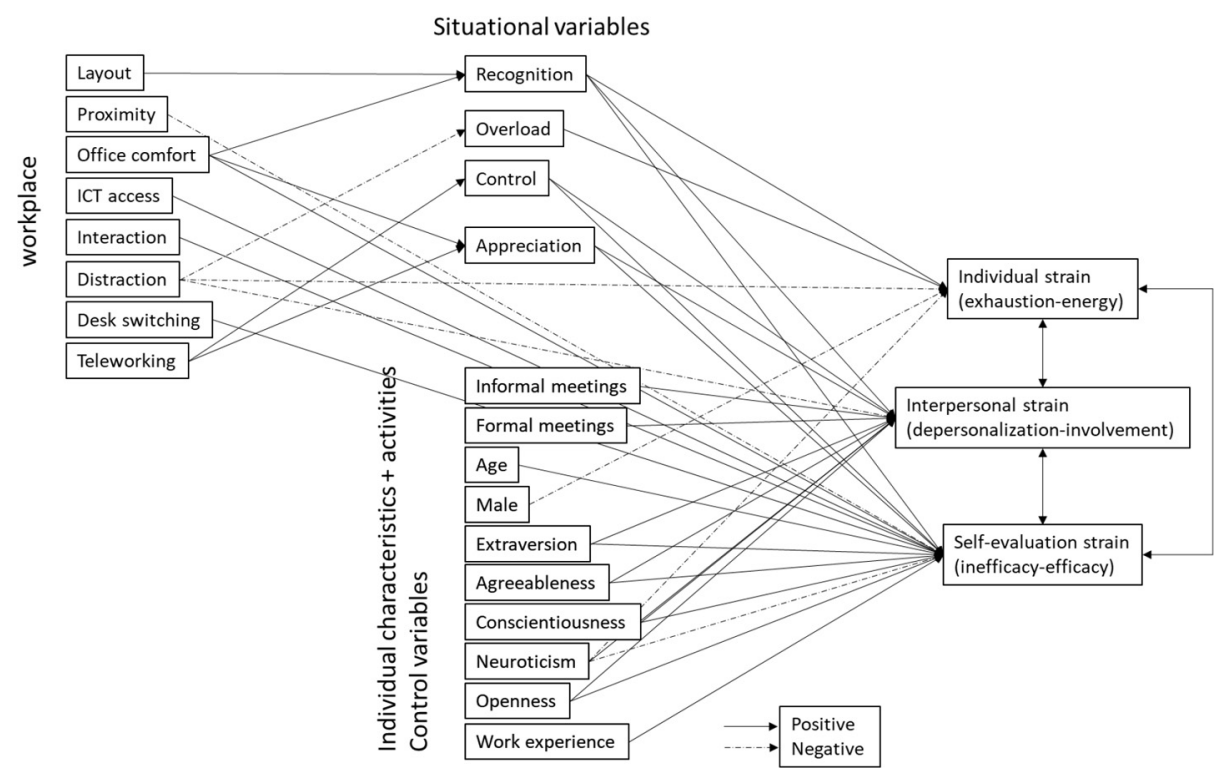




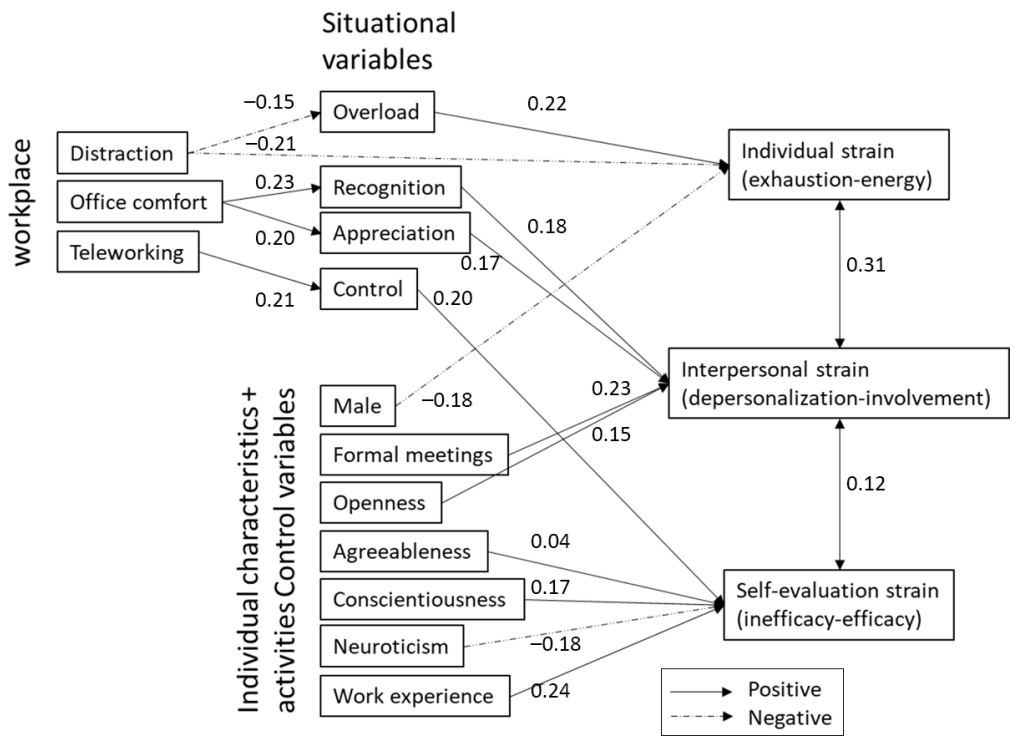

Burnout and engagement dimensions

289

Figure 3.

Final model after path analysis

More conscientious ( $\beta=0.17)$ and more agreeable $(\beta=0.04)$ personalities and workers with more work experience (in years at this employer; $\beta=0.24$ ) also score higher on efficacy, while more neurotic persons score lower $(\beta=-0.18)$.

\section{Discussion, implications and limitations}

Impact of activity-based workplaces on employees' position on the burnout-engagement continuum

Hypothesis $H 1$ (ABW characteristics have a direct effect on an employee's position on the $\mathrm{BEC}$ ) can only be partially accepted for office use. Only one significant, negative direct relation came forward, between distraction and the individual strain (exhaustion-energy) of the BEC. A lot of distractions can be frustrating, which costs energy on its own and people have to work longer to get their work done by making up for a lost time. There is not much research yet on how to deal with distractions. Most studies on acoustics and noise focus on sound levels (Keränen and Hongisto, 2013) or noise effects on satisfaction (Kim and De Dear, 2013) but not on (mental) health of employees. With the trend towards increased open offices, this deserves further research into the effects of technologies such as sound masking (Jahncke et al., 2016) and optimising coping behaviour. Contrary to previous studies on productivity (Haynes, 2007b), distraction did not relate to the self-evaluation strain. As there was no link between the individual and self-evaluation strain, there is also no indirect effect of distraction on efficacy, which is unexpected. As many respondents in this sample rated their efficacy very high, there might be a restriction of range in the dependent variable. All the other ABW characteristics did not relate to the self-evaluation strain in the path model either, where previous studies suggested a relationship with comfort (Bae et al., 2017) and ICT access (Nurmilaakso, 2009).

That desk-switching supports people's efficacy is one of the basic assumptions of ABW, but it has not been proven in studies and again is not confirmed here. Previous work suggests that task-switching triggers overload (Demerouti et al., 2014), but for desk-switching 
JCRE 22,4

(which is supposed to be based on switching tasks) this is not confirmed by our findings. Perhaps, for desk switching this is only the case when there are "negative" reasons (e.g. distraction) causing the switch (Hoendervanger et al., 2016). Claiming the same desk by personalising does not seem to support the efficacy or provide less exhaustion either. Perhaps, those who claim desks, do this for different reasons than stress, for example, to express status or to be able to use a preferred workplace every day.

Also, surprising is the lack of a relation between interaction and interpersonal strain (involvement). Where the importance of formal meeting activities for one's work was related to increased involvement in the model, actually having more social or work-related interactions was not. As involvement definitions are generally based on communication processes (Lopes et al., 2017), this seems counterintuitive. On the other hand, the actual interactions might not have provided a positive experience to the employees. Clearly, further research on office use is needed to fully understand $\mathrm{ABW}$ environments. It would also be interesting to replicate this research amongst people with more extensive burnout symptoms.

Hypothesis H4 (ABW characteristics have an indirect effect on employee's position on the $\mathrm{BEC}$ via the situational variables) can be accepted more strongly. First, where distraction already had a direct effect, there is additionally a mediated effect through a negative effect on overload. Remarkably, the data do not only suggest that an increase in overload ("I have too much work to do") increases feelings of energy but also that distraction decreases perceived overload. A lack of (auditory) privacy is generally associated with greater feelings of exhaustion (Bakker et al., 2014), but maybe there are also welcome forms of distraction, which make people relax for a moment. A large part of the sample scored high on the individual strain (more energy), so, perhaps, they get energy from having a lot of work to do. However, the continuation of this situation might lead to burnout in the long run. Clearly, distraction in the office deserves further research.

Second, perceived office comfort relates significantly to both feelings of recognition and appreciation. Like in earlier research (Maslach and Leiter, 2008), such feelings increase the involvement of workers (interpersonal strain). One of the major dilemmas in designing office comfort remains that what is optimal for one person or group may not be optimal for other people (Bitner, 1992). There exist significant individual differences in preferences (Wang et al., 2018) and Budie et al. (2019) showed that those using the open spaces in ABWs a lot find comfort even more important.

Third, teleworking improved efficacy via increased control. While teleworking provides some autonomy, and thus control, Hoornweg et al. (2016) showed that there might be a limit to this effect, as the effect on productivity changed from positive to negative with a higher telework intensity. Also, telecommuters experience more time pressure in the long run, while making longer work hours (Peters and Van der Lippe, 2007), although in this sample this did not lead to more exhaustion. The increased perceived efficacy could also be caused by the fact that the respondents found a distraction-free environment at home or a better work-life balance.

The expected indirect relations between office layout and all BEC dimensions through recognition were not confirmed in the path analysis. So, relations of office layout design with the workload and interpersonal relations (De Croon et al., 2005) and control (Vischer, 2007) could not be confirmed. In general, all layout items scored a mean between 3 and 4 on a fivepoint scale indicating that workers in the sample perceive a good fit between their needs and abilities and the layout of their ABW. Perhaps, there was too little variation in layout quality to identify an effect. Another explanation might be that the high demands of an open ABW environment (noise-causing exhaustion and less efficacy) are compensated by appropriate 
resources (variety in spaces, facilities), as put forward in the Job-demands-resources model by Bakker and Demerouti (2007). Further research should shed more light on whether and how the ABW layout design affects burnout and engagement.

\section{Burnout-engagement continuum and personal control variables}

It was not completely unexpected that no relationships between the individual and selfevaluation strain were found in the path analyses. Others (Lee and Ashforth, 1996) found relatively low correlations of professional efficacy with both other dimensions as well. The relationship between the individual and interpersonal strain was confirmed, which is in line with the idea that these form the core of burnout (Green et al., 1991).

Hypothesis H2 (Individual control variables affect an employee's position on the BEC) and H3 (Situational variables affect an employee's position on the BEC) are confirmed, but less complete than expected. For example, Alarcon et al. (2009) found that neurotic workers feel less energetic and experience more exhaustion, while in this study the neuroticism trait only relates negatively to efficacy. Previous research (Langelaan et al., 2006) claims that high neuroticism is the core antecedent of burnout, whereas people who score high on work engagement are characterised by low neuroticism in combination with high extraversion. The positive relation between openness and efficacy is also not confirmed, nor are previous findings of a relation between neuroticism and the interpersonal dimension (Schaufeli and Enzmann, 1998). It is clear that personality plays a role, but further research with larger and more diverse samples is necessary to gain more insight into how personality influences the $\mathrm{BEC}$ in an $\mathrm{ABW}$ context. Also, the findings regarding the effect on gender oppose that of Maslach et al. (2001), as men scored higher on exhaustion than women.

As expected, more experienced workers are more likely to see themselves as efficacious. Maslach et al. (2001) argued that age is related to work experience, suggesting that the risk of burnout is higher in an earlier phase of ones' career, but in this study, age was not related to any of the BEC dimensions. Regarding the importance of activities, workers who consider formal meetings more important show higher involvement. This does not apply to informal meetings. Further research should identify why this might be the case.

\section{Limitations of the study}

The study of complex phenomena such as burnout and engagement would benefit from longitudinal research. Due to the cross-sectional design of our study, it is impossible to derive causal relationships. Besides being a cross-sectional survey, this study was limited to the perceived impact of the physical environment, workers' activities, individual characteristics and work-related situational variables on burnout/engagement. The $R^{2}$ values suggest that additional variables exist that explain workers' position on the BEC dimensions.

The sample only included Dutch respondents and was relatively small. Although the current sample showed to be sufficiently large to conduct an appropriate path analysis, the limited size of the sample and a large number of influencing variables allowed to identify only relatively strong relationships. Not identifying relationships does not mean that they do not exist, but probably they are not sufficiently strong to be identified with the present size of the sample. A larger sample might have resulted in the identification of more relationships between the many independent variables and the burnout-engagement dimensions. The sample also includes workers from many different organisations. However, apart from being an official organisation, no further information about these organisations was available. Also, the findings can only be an indication of the Dutch context in which the data were gathered.
Burnout and engagement dimensions 
JCRE 22,4
While the burnout-engagement dimensions have been measured by validated measures, this does not (yet) apply to some of the independent variables. Additionally, using a more extended questionnaire (e.g. all 29 statements derived from the AWS, rather than the selection of 11 statements in this study) would be worthwhile to conduct more in-depth analyses of the relationships between the physical workplace characteristics, control variables and other potentially relevant variables, if the sample had been bigger.

The current study is partly exploratory (data-driven decisions, which variables to include in the path analysis) and partly theory-driven (testing hypotheses of interrelationships between families of independent, mediating and control variables and the $\mathrm{BEC}$ ). When a more extended theory is available, follow-up research could focus on more detailed hypotheses regarding single variables.

Besides larger samples, qualitative research using workshops with medical experts, business managers, CRE and facilities managers, human resource managers and wellinformed employees and analyses of sick leave data should be used to further validate the scales of the BEC and its relationship with ABW characteristics.

\section{Practical implications}

Especially office use requires more attention of workplace managers in practice when implementing the ABW concept. CRE managers aiming at mentally healthy workplaces should focus on offering a low distraction, comfortable environment. Workers should have the opportunity (and the organisational culture, Babapour, 2019) to isolate themselves from distraction when necessary, by providing various types of workplaces that support concentration (e.g. cell-offices, quiet areas, private spaces) and/or clear use-protocols in more open environments. Furthermore, CRE managers are recommended to support teleworking to a certain extent, to keep employees feeling in control but still connected to the organisation and their colleagues. In all cases, individual preferences should be taken into account as well.

\section{Conclusion}

Overload showed to be the strongest predictor of the individual (exhaustion-energy) dimension of the BEC, the importance of formal interaction of the interpersonal (cynicisminvolvement) dimension and work experience of the self-evaluation (inefficacy-efficacy) dimension. Because CRE is a supportive resource, it makes sense that work and individual characteristics have a larger effect on employees' mental health than the CRE. However, the standardised coefficients of the ABW constructs were of a similar size as those of the individual and situational variables. So, although neglected in previous studies, the physical work environment should clearly be included in future studies on burnout and engagement in ABWs as well. An additional novelty of this paper is that several general assumptions of ABW did not come forward in this analysis and clearly need more research to show whether these expectations are met in practice.

\section{References}

Alarcon, G., Eschleman, K.J. and Bowling, N.A. (2009), "Relationships between personality variables and burnout: a meta-analysis", Work and Stress, Vol. 23 No. 3, pp. 244-263.

Albrecht, S.L. (Ed.) (2010), "Handbook of employee engagement: perspectives", Issues, Research and Practice, Elgar, Glos. 
Appel-Meulenbroek, R., Kemperman, A., Kleijn, M. and Hendriks, E. (2015), "To use or not to use; which type of property should you choose? Predicting the use of activity-based offices", Journal of Property Investment and Finance, Vol. 33 No. 4, pp. 320-336.

Arif, M., Katafygiotou, M., Mazroei, A., Kaushik, A. and Elsarrag, E. (2016), "Impact of indoor environmental quality on occupant well-being and comfort: a review of the literature", International Journal of Sustainable Built Environment, Vol. 5 No. 1, pp. 1-11.

Aussems, R. (2019), "Healthy work environments. Impact of physical work environment on a burnoutengagement continuum in activity-based offices", MSc thesis, Eindhoven University of Technology, The Netherlands.

Babapour, M. (2019), "The quest for the room of requirement - why some activity-based flexible offices work while others do not", Doctoral thesis, Chalmers University of Technology, Sweden.

Bae, S., Asojo, A., Guerin, D. and Martin, C. (2017), "A post-occupancy evaluation of the impact of indoor environmental quality on health and well-being in office buildings", Journal of Organizational Psychology, Vol. 17 No. 6, pp. 25-36.

Bakker, A.B. and Demerouti, E. (2007), “The job demands - resources model: state of the art”, Journal of Managerial Psychology, Vol. 22 No. 3, pp. 309-328.

Bakker, A.B. and Demerouti, E. (2008), "Towards a model of work engagement”, Career Development International, Vol. 13 No. 3, pp. 209-223.

Bakker, A.B., Demerouti, E. and Sanz-Vergel, A.I. (2014), "Burnout and work engagement: the JD-R approach", Annual Review of Organizational Psychology and Organizational Behavior, Vol. 1 No. 1, pp. 389-411.

Bitner, M.J. (1992), "Servicescapes: the impact of physical surroundings on customers and employees", Journal of Marketing, Vol. 56 No. 2, pp. 57-71.

Brenninkmeijer, V. and Van Yperen, N. (2003), "How to conduct research on burnout: advantages and disadvantages of a unidimensional approach in burnout research", Occupational and Environmental Medicine, Vol. 60 No. >90001, pp. i16-i20.

Brunia, S., De Been, I. and Van der Voordt, T. (2016), "Accommodating new ways of working: lessons from best practices and worst cases", Journal of Corporate Real Estate, Vol. 18 No. 1, pp. 30-47.

Budie, B., Appel-Meulenbroek, R., Kemperman, A. and Weijs-Perrée, M. (2019), "Employee satisfaction with the physical work environment: the importance of a need-based approach", International Journal of Strategic Property Management, Vol. 23 No. 1, pp. 36-49.

Clements-Croome, D. and Li, B. (1997), "Assessment of the influence of indoor environment on job stress and productivity of occupants in offices", Proceedings of Healthy Buildings/IAQ '97, Washington, DCD.C., September 27-October 2, pp. 495-500.

De Been, I., Van der Voordt, D.J.M. and Haynes, B.P. (2016), "Productivity”, in Jensen, P.A. and Van der Voordt, T. (Eds), Facilities Management and Corporate Real Estate Management as Value Drivers: How to Manage and Measure Adding Value, Routledge, London/New York, NY, pp. 140-155.

De Croon, E., Sluiter, J., Kuijer, P.P. and Frings-Dresen, M. (2005), "The effect of office concepts on worker health and performance: a systematic review of the literature”, Ergonomics, Vol. 48 No. 2, pp. 119-134.

Demerouti, E., Derks, D., Ten Brummelhuis, L.L. and Bakker, A.B. (2014), "New ways of working: impact on working conditions, work-family balance, and well-being", in Korunka C. and Hoonakker P. (Eds), The Impact of ICT on Quality of Working Life, Springer, Dordrecht, The Netherlands, pp. 123-141.

Edwards, J.R., Caplan, R.D. and Harrison, R.V. (1998), "Person-environment fit theory: conceptual foundations, empirical evidence, and directions for future research", in Cooper C.L. (Ed.), Theories of Organizational Stress, Oxford University Press, Oxford, pp. 28-67. 
JCRE 22,4

Engelen, L., Chau, J., Young, S., Mackey, M., Jeyapalan, D. and Bauman, A. (2019), "Is activity-based working impacting health, work performance and perceptions? A systematic review", Building Research and Information, Vol. 47 No. 4, pp. 468-479.

Fredrickson, B. (2001), "The role of positive emotions in positive psychology: the broaden-and-build theory of positive emotions", American Psychologist, Vol. 56 No. 3, pp. 218-226.

Freudenberger, H.J. (1974), "Staff burnout”, Journal of Social Issues, Vol. 30 No. 1, pp. 159-165.

Frone, M.R. and Tidwell, M.-C.O. (2015), "The meaning and measurement of work fatigue: development and evaluation of the three-dimensional work fatigue inventory (3D-WFI)", Journal of Occupational Health Psychology, Vol. 20 No. 3, pp. 273-288.

Gorgievski, M.J., Van der Voordt, T.J.M., Van Herpen, A.G.A. and Van Akkeren, S. (2010), "After the fire: new ways of working in an academic setting”, Facilities, Vol. 28 Nos. 3/4, pp. 206-224.

Grawitch, M.J., Gottschalk, M. and Munz, D.C. (2006), "The path to a healthy workplace: a critical review linking healthy workplace practices, employee well-being, and organizational improvements", Consulting Psychology Journal: Practice and Research, Vol. 58 No. 3, pp. 129-147.

Green, D.E., Walkey, F.H. and Taylor, A.J. (1991), "The three-factor structure of the maslach burnout inventory: a multicultural, multinational confirmatory study", Journal of Social Behavior and Personality, Vol. 6 No. 3, pp. 453-473.

Haapakangas, A., Hallman, D.M., Mathiassen, S.E. and Jahncke, H. (2019), "The effects of moving into an activity-based office on communication, social relations and work demands; a controlled intervention with repeated follow-up”, Journal of Environmental Psychology, Vol. 66, pp. 1-8.

Haynes, B.P. (2007a), "Office productivity: a theoretical framework", Journal of Corporate Real Estate, Vol. 9 No. 2, pp. 97-110.

Haynes, B.P. (2007b), "The impact of the behavioural environment on office productivity", Journal of Facilities Management, Vol. 5 No. 3, pp. 158-171.

Haynes, B.P. and Price, I. (2004), "Quantifying the complex adaptive workplace”, Facilities, Vol. 22 Nos 1/2, pp. 8-18.

Haynes, B., Suckley, L. and Nunnington, N. (2017), "Workplace productivity and office type", Journal of Corporate Real Estate, Vol. 19 No. 2, pp. 111-138.

Hoendervanger, J.G., De Been, I., Van Yperen, N.W., Mobach, M.P. and Albers, C.J. (2016), "Flexibility in use: switching behaviour and satisfaction in activity-based work environments", Journal of Corporate Real Estate, Vol. 18 No. 1, pp. 48-62.

Hoornweg, N., Peters, P. and Van der Heijden, B. (2016), "Finding the optimal mix between telework and office hours to enhance employee productivity: a study into the relationship between telework intensity and individual productivity, with mediation of intrinsic motivation and moderation of office hours", in de Leede J. (Ed.), New Ways of Working Practices: Antecedents and Outcomes (the Advanced Series in Management), Bingly, pp. 1-28.

Jahncke, H., Björkeholm, P., Marsh, J.E., Odelius, J. and Sörqvist, P. (2016), "Office noise: can headphones and masking sound attenuate distraction by background speech?”, Work, Vol. 55 No. 3, pp. 505-513.

Kahn, R.L. and Byosiere, P. (1992), "Stress in organizations", in Dunnette M.D. and Hough L.M. (Eds), Handbook of Industrial and Organizational Psychology, Vol. 3, Consulting Psychologists Press, Palo Alto, CA, pp. 571-650.

Keränen, J. and Hongisto, V. (2013), "Prediction of the spatial decay of speech in open-plan offices", Applied Acoustics, Vol. 74 No. 12, pp. 1315-1325.

Kim, J. and De Dear, R. (2013), "Workspace satisfaction: the privacy-communication trade-off in openplan offices”, Journal of Environmental Psychology, Vol. 36, pp. 18-26.

Kroemer, A.D. and Kroemer, K.H. (2016), Office Ergonomics: Ease and Efficiency at Work, CRC Press. 
Langelaan, S., Bakker, A.B., Van Doornen, L.J. and Schaufeli, W.B. (2006), "Burnout and work engagement: do individual differences make a difference?", Personality and Individual Differences, Vol. 40 No. 3, pp. 521-532.

Lee, R.T. and Ashforth, B.E. (1996), "A Meta-analytic examination of the correlates of the three dimensions of job burnout", Journal of Applied Psychology, Vol. 81 No. 2, pp. 123-133.

Leiter, M.P. and Maslach, C. (2005), “A mediation model of job burnout”, In Antoniou A.S.G.and Cooper C.L. (Eds), Research Companion to Organizational Health Psychology, Edward Elgar, Cheltenham, pp. 544-564.

Burnout and engagement dimensions

Leiter, M.P. and Maslach, C. (2003), "Areas of worklife: a structured approach to organizational predictors of job burnout", in Perrewé P. and Ganster D.C. (Eds), Research in Occupational Stress and Well Being, Vol. 3, Emotional and physiological processes and positive intervention strategies, pp. 91-134. JAI Press/Elsevier, Oxford.

Lopes, H., Calapez, T. and Lopes, D. (2017), "The determinants of work autonomy and employee involvement: a multilevel analysis", Economic and Industrial Democracy, Vol. 38 No. 3, pp. 448-472.

Mann, S. and Holdsworth, L. (2003), "The psychological impact of teleworking: stress, emotions and health", New Technology, Work and Employment, Vol. 18 No. 3, pp. 196-211.

Maslach, C. and Leiter, M.P. (1997), The Truth About Burnout: How Organizations Cause Personal Stress And What To Do About It, Jossey-Bass, San Francisco, CA.

Maslach, C. and Leiter, M.P. (2008), "Early predictors of job burnout and engagement", Journal of Applied Psychology, Vol. 93 No. 3, pp. 498-512.

Maslach, C., Schaufeli, W.B. and Leiter, M.P. (2001), “Job burnout”, Annual Review of Psychology, Vol. 52 No. 1, pp. 397-422.

Nurmilaakso, J.M. (2009), "ICT solutions and labor productivity: evidence from firm-level data", Electronic Commerce Research, Vol. 9 No. 3, pp. 173-181.

Oseland, N. (2009), "The impact of psychological needs on office design", Journal of Corporate Real Estate, Vol. 11 No. 4, pp. 244-254.

Parent-Lamarche, A. and Marchand, A. (2019), "Well-being at work from a multi-level perspective: what is the role of personality traits?", International Journal of Workplace Health Management, Vol. 12 No. 5, pp. 298-317.

Parker, S.K. and Griffin, M.A. (2011), "Understanding active psychological states: embedding engagement in a wider nomological net and closer attention to performance", European Journal of Work and Organizational Psychology, Vol. 20 No. 1, pp. 60-67.

Peters, P. and Van der Lippe, T. (2007), "The time-pressure reducing potential of telehomeworking: the Dutch case", The International Journal of Human Resource Management, Vol. 18 No. 3, pp. 430-447.

Quińones, M.A., Ford, J.K. and Teachout, M.S. (1995), “The relationship between work experience and job performance: a conceptual and Meta-analytic review", Personnel Psychology, Vol. 48 No. 4, pp. 887-910.

Rammstedt, B. and John, O.P. (2007), "Measuring personality in one minute or less: a 10-item short version of the big five inventory in English and German", Journal of Research in Personality, Vol. 41 No. 1, pp. 203-212.

Rennecker, J. and Derks, D. (2012), "Email overload: fine tuning the research lens", in Derks D. and Bakker A.B. (Eds), The Psychology of Digital Media @ Work, Psychology Press, London.

Rothe, P., Lindholm, A., Hyvönen, A. and Nenonen, S. (2011), "User preferences of office occupiers: investigating the differences", Journal of Corporate Real Estate, Vol. 13 No. 2, pp. 81-97.

Schaufeli, W.B. and Bakker, A.B. (2004), "Job demands, job resources, and their relationship with burnout and engagement: a multi-sample study", Journal of Organizational Behavior, Vol. 25 No. 3, pp. 293-315. 
JCRE 22,4

Schaufeli, W.B. and Enzmann, D. (1998), The Burnout Companion to Study and Practice: A Critical Analysis, Taylor and Francis, London.

Schaufeli, W.B., Bakker, A.B. and Van Rhenen, W. (2009), "How changes in job demands and resources predict burnout, work engagement, and sickness absenteeism”, Journal of Organizational Behavior, Vol. 30 No. 7, pp. 893-917.

Schaufeli, W.B., Leiter, M.P., Maslach, C. and Jackson, S.E. (1996), "The maslach burnout inventory general survey", in Maslach, C. Jackson S.E. and Leiter M.P. (Eds), MBI Manual. Consult. Psychol, 3rd ed., Palo Alto, CA, pp. 19-26.

Schaufeli, W.B., Salanova, M., González-Romá, V. and Bakker, A.B. (2002), "The measurement of engagement and burnout and: a confirmative analytic approach", Journal of Happiness Studies, Vol. 3 No. 1, pp. 71-92.

Seppänen, O.A. and Fisk, W. (2006), "Some quantitative relations between indoor environmental quality and work performance or health", HVAC and R Research, Vol. 12 No. 4, pp. 957-973.

Shirom, A., Melamed, S., Toker, S., Berliner, S. and Shapira, I. (2005), "Burnout and health review: current knowledge and future research directions", International Review for Industrial and Organizational Psychology, Vol. 20, pp. 269-307.

Tabachnick, B.G. and Fidell, L.S. (2007), Using Multivariate Statistics, 5th ed., Allyn and Bacon, Boston.

TNO (2015), "Factsheet TNO: Werkstress, burn-out and verzuim in cijfers. Gepubliceerd op 16-112015”, Ministerie van Sociale Zaken en Werkgelegenheid.

Van der Voordt, D.J.M. (2004), "Productivity and employee satisfaction in flexible workplaces", Journal of Corporate Real Estate, Vol. 6 No. 2, pp. 133-148.

Van Steenbergen, E.F., Van der Ven, C., Peeters, M.C.W. and Taris, T.W. (2018), "Transitioning towards new ways of working: do job demands, job resources, burnout, and engagement change?", Psychological Reports, Vol. 121 No. 4, pp. 736-766.

Vischer, J.C. (2007), “The effects of the physical environment on job performance: towards a theoretical model of workspace stress", Stress and Health, Vol. 23 No. 3, pp. 175-184.

Vos, P., Van Meel, J. and Dyks, A. (1999), The Office, the Whole Office and Nothing but the Office, Delft University of Technology, Delft, The Netherlands.

Wang, Z., de Dear, R., Luo, M., Lin, B., He, Y., Ghahramani, A. and Zhu, Y. (2018), "Individual difference in thermal comfort: a literature review", Building and Environment, Vol. 138, pp. 181-193.

\section{Further reading}

Appel-Meulenbroek, R., Clippard, M. and Pfnür, A. (2018), "The effectiveness of physical office environments for employee outcomes: an interdisciplinary perspective of research efforts", Journal of Corporate Real Estate, Vol. 20 No. 1, pp. 56-80.

\section{Corresponding author}

Rianne Appel-Meulenbroek can be contacted at: h.a.j.a.appel@tue.nl

For instructions on how to order reprints of this article, please visit our website: 